\title{
¿A QUIÉN PERTENECEN LOS MARES? EVOLUCIÓN DE LA SOBERANÍA MARÍTIMAA LO LARGO DE LA HISTORIA
}

\author{
Francisco José Torres Alfosea \\ Departamento de Análisis Geográfico Regional y Geografía Física \\ Universidad de Alicante
}

\section{RESUMEN}

En este trabajo se pretende demostrar que la mayor parte de los conflictos relacionados con la soberanía marítima se deben a dos motivos: por un lado una mala definición de los territorios que componen la interfase tierra-mar (costa, litoral y sus límites respectivos), y por otro, una redacción ambigua en los documentos internacionales (esencialmente la III Convención de las Naciones Unidas sobre Derecho del Mar), que ha propiciado actuaciones unilaterales y conflictos de intereses entre naciones con costas adyacentes o bien con costas frente a frente. Se argumenta, además, que ninguna de las dos razones es casual, ni fruto de la ignorancia o de la dejadez. Al contrario, se trata de redacciones conscientes que responden al interés de los estados con acceso al mar por desarrollar un marco normativo flexible, en el que poder reclamar la soberanía de la mayor parte de espacio marino, a expensas de espacios de uso común como la alta mar o la zona.

Palabras clave: océanos, mares, soberanía marítima, CNUDM, mar territorial, líneas de base, aguas interiores, zona económica exclusiva, ZEE, plataforma continental.

\section{ABSTRACT}

In this paper we try to demonstrate that most of the maritime sovereignty-related conflicts are due to two reasons: on the one hand a bad definition of the territories that make up the interface land-sea (shore, coastline and their respective limits), and on the other, ambiguous wording in international documents (essentially the III of the UN Convention on Law of the Seas) that it has led to unilateral actions and conflicts of interest between Nations with adjacent coasts or coasts face-to-face. Moreover, none of the two reasons is casual, or as a result of ignorance or of the neglect. On the contrary, it's conscious text that responds to the interests of the States with access to the sea to 
develop a flexible normative framework, in which to claim the sovereignty of most of marine space, at the expense of spaces in common, such as the high seas or the area.

Key words: oceans, seas, maritime sovereignty, UNCLOS, territorial waters, baselines, internal waters, economic exclusive zone, EEZ, continental shelf.

\section{UNA NECESARIA PRECISIÓN TERMINOLÓGICA}

En castellano se emplean, a veces de forma indistinta, dos términos geográficos que hacen referencia al espacio comprendido entre las tierras emergidas y las aguas marinas. Costa y litoral, muchas veces entendidos como sinónimos, aluden sin embargo a territorios de diferente superficie y naturaleza. Probablemente por influencia del inglés, donde tan sólo coast es empleado, en castellano tendemos a utilizar costa y litoral como conceptos intercambiables, cuando no lo son. Conviene detenerse brevemente para clarar las diferencias entre ambos conceptos, que van mucho más allá de una mera cuestión semántica, y afectan directamente a la capacidad de planificación y ordenación de estos espacios. De hecho, buena prueba de la necesidad de aclarar el significado de estos términos es la ausencia de una adecuada definición en nuestro ordenamiento jurídico, que ha repercutido en buena parte de los documentos de planificación litoral. En España, por ejemplo, se han aprobado leyes de aguas con influencia en las marinas, (como la de 1866), leyes de puertos $(1880,1928,1992)$ y leyes de costas $(1969,1988$ y 2013), pero ninguna ley del litoral. Es más, ni siquiera en las leyes de costas se define qué es la costa, ni el litoral, ni se diferencia entre ellas, lo que no deja de ser una omisión preocupante. Se definen razonablemente bien, eso sí, los bienes de dominio público, convirtiendo así terminos puramente geográficos en simples figuras de protección jurídica, lo que limita la aplicación geográfica (por tanto territorialmente integral) de la ley. Sobre la necesidad de reflexionar acerca de los límites de estos espacios han escrito recientemente Barragán y de Andrés (2016), especialmente por la relevancia que tiene para el diseño de políticas institucionales de ordenación integrada de espacios costeros.

El término costa proviene del latín costam, que significa literalmente «lado» o implica «condición de lateral». Mantenemos en castellano la palabra costado para hacer referencia al lado del ser humano, como en catalán se emplea la expresión al costat, con el sentido de «al lado de». La etimología, por lo tanto, refleja el final de algo, su borde exterior, aunque lógicamente la precisión es vaga. La ambigüedad se mantiene si acudimos a las definiciones que aportan los diccionarios generalistas: el DRAE define el término como la orilla del mar, de un río, de un lago, etc. y tierra que está cerca de ella ${ }^{1}$, que es una definición

1. http://dle.rae.es/?w=costa. 
reproducida con leves variaciones en diccionarios de otras editoriales, como VOX (tierra que bordea la orilla del mar).

Pero los términos están definidos con precisión desde hace casi sesenta años, si bien en obras de contenido específicamente geográfico, como el Diccionario de términos geográficos de Moore (1957) donde costa queda definida como la parte de la tierra que bordea la orilla del mar u otra porción extensa de agua, experimentando así la influencia directa de las olas. Esta definición deja clara la relación directa que debe existir entre oleaje y costa. Por lo tanto, en principio ésta no puede ser nunca una línea, sino en todo caso una franja mensurable como mínimo en metros. Esta vinculacion entre oleaje y costa, a pesar de formularse hace tiempo, sin embargo no ha sido recogida en ningún cuerpo normativo.

Y esto resulta paradójico, porque no se puede aducir ignorancia por parte del legislador. Al menos no en el caso de la ley de costas de 1988. En efecto, en 1987, con motivo de los trabajos previos encaminados a la redaccion de la ley 22/1988, de 28 de julio, de Costas, el ya desaparecido Instituto del Territorio y el Urbanismo (ITUR) elaboró un documento de gran interés titulado Análisis del litoral español. Diseño de políticas territoriales, en el que daba la que probablemente sea la definición más acertada en castellano del término costa, como la estrecha franja, de unas decenas de metros como máximo, que está o puede estar en contacto directo con el mar. A pesar de su aparente simplicidad, esta breve frase contiene las tres características que deben darse para poder definir un espacio como costa: no es una línea, sino una franja mensurable en metros (aunque excepcionalmente en otras magnitudes) y necesita forzosamente el contacto directo con el $\mathrm{mar}^{2}$. Éste se produce a través de dos agentes de la dinámica marina: el oleaje (ya citado por Moore) y el recorrido de las mareas. La costa es, pues, lo que desde un punto de vista geográfico llamaríamos el estero, o zona que queda al descubierto sólo en bajamar. A pesar de contar con estos mimbres, el legislador de 1988, para redactar la ley de costas, evitará este término y llamará a este espacio la zona marítimo-terrestre, que quedará definida como el

2. Sólo en costas macromareales con carreras de marea excepcionalmente amplias puede medirse la costa en kilómetros. Es conocido el caso de la bahía de Fundy en Nueva Brunswick, donde el Servicio Hidrográfico de Canadá ha registrado 17 metros de amplitud mareal, poco más de los 16'8 m. acreditados en la bahía de Ungawa, también canadiense, al norte de la Península del Labrador. Se trata de valores máximos, pero no del máximo absoluto que se registró en Fundy la noche del 4 al 5 de octubre de 1869, cuando a la pleamar máxima viva equinoccial se sumó la influencia de un ciclón tropical, lo que elevó las aguas de la bahía 21'6 m. En estos lugares, así como en las costas orientales de Bretaña (Saint-Malo, Mont Saint Michel), donde el registro alcanza 14'5 m., las aguas al retirarse despejan una zona de varios kilómetros, convirtiendo así a la costa de estos lugares en la más amplia del mundo. En sentido contrario, las costas verticales (acantilados tipo plunging como los franceses de Etretat, los irlandeses de Moher o los del Morro del Toix en Alicante) impiden la entrada de oleaje al interior y por tanto en ellos la costa es una línea recta, y no una franja. Salvadas estas dos excepciones, por exceso y por defecto, la costa se ajusta a la definición indicada. 
espacio que alternativamente cubren y descubren las aguas en el movimiento de la marea y cuyo límite interior vendrá marcado por la cota hasta la que llegan las olas en los temporales conocidos ${ }^{3}$. De forma absurda, consciente -o muy probablemente no-, la ley de costas se quedó sin costa y la convirtió en zmt. De ese modo se evitaba tener que distinguir entre tipos de costa (arenosas, de gravas, deltaicas, rasas, plataformas de abrasión...), es decir, se evitaba que la geografía importara para la ordenación costera, y se reducía su definición a la mera acción del oleaje o de las mareas.

Realmente la costa no sólo estaba bien definida por el ITUR. Casi por esas mismas fechas, poco después, se publica el Diccionario de Geografía de Pierre George (1991), donde el vocablo queda definido como el dominio geomorfológico comprendido, en sentido estricto, entre la parte más alta y más baja de las mareas, pero entendido en un sentido mucho más amplio, como el espacio influenciado por las fuerzas marinas activas en el continente. George, pues, está remarcando la importancia mareal para la definición de la costa, e introduce al mismo tiempo una interpretación más amplia, que dará pie al término litoral.

Para este vocablo, la definicion etimológica no aporta distinción con la costa. Derivado del latín litus oris, borde de la tierra, la palabra deviene en litoralem en latín bajomedieval, para adquirir su forma actual en fecha más reciente, ya en castellano. Sin embargo es un término tradicionalmente poco empleado fuera del vocabulario de la ordenación del territorio. De hecho, una de las primeras veces que lo registramos en castellano es en 1980, en el documento La ordenación integrada del litoral en la $\mathrm{CE}$, elaborado por la entonces llamada Comunidad Económica Europea. Allí se definía este término como la parte del territorio que comprendiese una franja que se extendiera a partir de la linea de costa hacia el interior sobre una profundidad de al menos $10 \mathrm{~km}$.

Lo cierto es que la definición no puede ser más ambigua y contiene algunas imprecisiones. Aclara, al menos, que se trata de una zona diferente de la costa, pero asigna a esta última una entidad lineal $-\mathrm{y}$ ya sabemos que no la tiene- $\mathrm{y}$ limita el litoral sólo hacia tierra adentro, cuando, como veremos, tiene también límites exteriores, muy complejos, que darán lugar a las disputas por soberanía marítima. Por último, los $10 \mathrm{~km}$ son, no es necesario decirlo, una arbitrariedad sin correspondencia alguna con la variada morfología costera europea.

Pero las vaguedades no son exclusivas de documentos europeos. Ya se ha comentado que las leyes de costas en España no definen qué es la costa, ni qué es el litoral. Si acaso, lo más similar que encontramos a una definición de estos conceptos aparece en la Exposición de Motivos de la ley 22/88, de costas, donde se habla de una orla litoral de una anchura de unos cinco kilómetros. Resulta llamativa esta imprecisión, máxime después de haberse elaborado doce años

3. Ley $22 / 1988$, de costas, art. 3.1. 
antes, en 1976, el Plan Indicativo de Usos sobre el litoral español (PIDU), que reflejaba de forma precisa a escala 1:5.000 toda la costa nacional y permitía pronunciarse con mayor rigor.

Tampoco los redactores de la ley de costas podían argumentar desconocimiento o ignorancia porque además contaban ya con el documento citado de 1987 elaborado por el ITUR. En él se definía el litoral con una precisión tan clara que resulta llamativo (o sospechoso) que no se recogiera en el texto final de la ley: el área terrestre contigua a la costa, de amplitud variable -habitualmente entre 3 y 12 kilómetros, según las características o actividades objeto de análisis-a las que habría que sumar el área marina adyacente, cuya anchura depende del perfil de la plataforma continental, que llega hasta la isóbata de $200 \mathrm{~m}$.

Deja claro que litoral y costa son elementos diferentes; que el primero es mayor que el segundo, y de hecho lo integra; que se mide en kilómetros, aunque el ITUR no fue tan rígido como para dar un umbral concreto, sino que aporta una horquilla, flexible, de entre 3 y 12 kilómetros, que estarán en función de las actividades que analicemos; por tanto el litoral es un espacio funcional, no definido por procesos físicos como la costa (donde oleaje y mareas son determinantes), y mucho más complejo; e iba más allá: el litoral tiene límites interiores, pero también exteriores, mar adentro, que dependerán del perfil de la plataforma continental. Resulta penoso que esta detallada y geográficamente buena definición, no trascendiera ese documento y se incorporara al articulado de la ley de costas que ya entonces estaba en una fase de borrador avanzado en el Congreso.

\section{LÍMITES EXTERIORES FÍSICOS DEL LITORAL}

El problema esencial es éste: si bien podemos delimitar con precisión la costa, atendiendo al recorrido de la marea o a la influencia del oleaje, sin embargo no podemos hacer lo mismo con el litoral, ni tierra adentro ni hacia el exterior. Al menos, no con la misma objetividad. Tierra adentro dependerá de cuál sea el criterio empleado, si el topográfico, el administrativo, el biológico, el climático, el jurídico... el litoral será más o menos extenso. Así, hablaremos de municipios litorales para referimos a aquellas entidades administrativas que tienen costa, o prelitorales si ocupan una posición más retranqueada; hablaremos de climas litorales si manifiestan la influencia de la cercanía marina, o hablaremos de tierras litorales si se encuentran comprendidas entre la costa y la línea de cumbres más próxima (con todos los matices posibles). La necesidad de conocimiento geográfico para trazar estos límites es evidente, y obliga a emplear criterios flexibles, complejos y muchas veces combinados entre sít.

4. Aunque escapa a los objetivos de este trabajo, la mala elección de esos límites interiores del litoral condiciona el éxito o el fracaso de una investigacion, o de un documento de ordenación 
Aguas adentro la complejidad no es menor, y es causa de frecuentes conflictos intra e internacionales. Para intentar delimitar cuáles son los límites exteriores del litoral se pueden manejar dos tipos de límites: los físicos y los administrativos.

Desde el punto de vista físico, el hecho definitorio es la plataforma continental. En definición sencilla podríamos decir que se trata de la prolongación submarina de los continentes (aunque se encuentra también alrededor de numerosas islas), de pendiente relativamente suave, y que termina cuando ésta comienza a aumentar, en el talud continental. Sin embargo, a pesar de tratarse de un espacio geomorfológico, la plataforma tiene una definición jurídica, aprobada en la I Convención de las Naciones Unidas sobre Derecho del Mar, celebrada en Ginebra en 1958. En ella, textualmente se indicaba que:

Los Estados Partes en la Convención han convenido en lo siguiente:

Artículo 1.

Para los efectos de estos artículos, la expresión plataforma continental designa:

a) el lecho del mar y el subsuelo de las zonas submarinas adyacentes a las costas pero situadas fuera de la zona del mar territorial, hasta una profundidad de 200 metros, o más allá de este límite hasta donde la profundidad de las aguas suprayacentes permita la explotación de los recursos naturales de dichas zonas;

b) el lecho del mar y el subsuelo de las regiones submarinas análogas, adyacentes a las costas de las islas ${ }^{5}$.

Una vez más nos encontramos ante una definición manifiestamente mejorable, ya que en ella se convierte un límite físico fácil de comprobar (en la medida que se puede acreditar la extensión submarina entre la costa y el inicio del talud continental) en un límite arbitrario (200 mts de profundidad no es un lugar que se corresponda necesariamente con el final de la plataforma), o bien un límite económico, ligado a la capacidad de la nación ribereña para explotar sus recursos naturales.

De los cuatro acuerdos sobre los que se debatió en Ginebra en 1958, éste sobre la plataforma continental logró consenso (no así otros, como veremos), por lo que, a pesar de la ambigüedad del texto y del mal análisis geográfico en

litoral. Así, las Directrices de actuación en el litoral de la Comunidad Valenciana que se redactaron en 1999 nunca fueron aplicables porque se empleó en ellas un criterio arbitrario, ageográfico, de un kilómetro tierra adentro (EPYPSA, 1999). Las Directrices regionales del litoral de Andalucía (Junta de Andalucía, 1990), sin embargo, optaron por una fórmula compleja, pero bien argumentada, definiendo unidades territoriales del litoral (acantilados, sierras litorales y prelitorales, playas...) y no sólo fueron aplicables sino que constituyen un ejemplo de buena ordenación del litoral.

5. Se puede consultar el texto íntegro de esta Convención en el apartado de tratados de Naciones Unidas: http://treaties.un.org/doc/Treaties/1964/06/19640610\%2002-10\%20AM/ Ch_XXI_01_2_3_4_5p.pdf 
el que incurre, fue aprobado y trasladado al derecho nacional de cada una de las naciones firmantes. Años después, en 1982, la definición mejoró con el texto aprobado en la III Convención, y desde entonces queda definida del siguiente modo:

La plataforma continental de un Estado ribereño comprende el lecho y el subsuelo de las áreas submarinas que se extienden más allá de su mar territorial y a todo lo largo de la prolongación natural de su territorio hasta el borde exterior del margen continental, o bien hasta una distancia de 200 millas marinas contadas desde las líneas de base a partir de las cuales se mide la anchura del mar territorial, en los casos en que el borde exterior del margen continental no llegue a esa distancia (...). El margen continental comprende la prolongación sumergida de la masa continental del Estado ribereño y está constituido por el lecho y el subsuelo de la plataforma, el talud y la emersión continental. No comprende el fondo oceánico profundo con sus crestas oceánicas ni su subsuelo ${ }^{6}$.

Esta definición, mucho más compleja que la anterior, abandona el criterio subjetivo de la profundidad y lo sustituye, cuando la plataforma no alcance las 200 millas náuticas, por otro de medición lineal en la superficie: desde las líneas de base hasta esa distancia, de forma que quedaría garantizado, al menos, ese espacio para la gestión de la nación ribereña siempre que no hubiera necesidad de pactar con otra nación. Se introduce así un concepto diferente, que podríamos llamar de establecimiento de límites administrativos exteriores del litoral, que abandona definitivamente el criterio geográfico en la delimitación de espacios de soberanía marítima a favor de límites de distancia, y que es el que rige en la actualidad.

\section{HISTORIA DE LA DELIMITACIÓN EXTERIOR ADMINISTRATIVA DEL LITORAL}

\section{La tierra domina el mar}

El trazado de límites «administrativos» en el mar resulta complejo, por cuanto en superficie no existen elementos de referencia, y los submarinos resultan de difícil localización y trazado. El uso -y la comodidad e intereses de las nacioneshan establecido que se empleen criterios terrestres para determinar las fronteras marítimas entre las naciones. Lacleta (2004) expresa esto con la frase la tierra domina el mar, expresiva sentencia que, debidamente analizada, a nuestro juicio permite tres interpretaciones:

1. La jurisdicción de un estado ribereño sobre el mar no depende de su superficie ni de su capacidad económica o militar, sino que está en funcion de la forma de su costa, y muy especialmente de la manera en

6. III Convención de las Naciones Unidas sobre Derecho del Mar (CNUDM), art. 76.1 y 76.3. La cursiva es nuestra. 
la que sus fronteras terrestres lleguen al mar. Un estado pequeño, por tanto, vecino de uno mayor, podrá tener mayor superficie marina bajo su dominio si este trazado fronterizo le es favorable.

2. A diferencia de lo que ocurre en tierra firme, donde los accidentes geográficos suelen servir de frontera entre dos naciones (Río Grande entre Estados Unidos y México, Pirineos entre España y Francia...), en los mares éstos no se emplean, por la dificultad de su identificación y control posterior. En realidad sólo se han empleado criterios geomorfológicos en muy contadas ocasiones para delimitar espacios de soberanía marítima entre naciones (Naciones Unidas, 2001) que por su interés, merecen ser mencionadas.

a. La controversia entre Indonesia y Australia por el mar de Timor y el mar de Arafura es probablemente la más significativa. Se resolvió en 1972 con una sentencia de la Corte Internacional de Justicia en la que se emplearon, por vez primera, criterios geomorfológicos submarinos para la delimitación de la frontera. Indonesia sostenía que había una única plataforma continental entre ambas naciones, y que por tanto la frontera debía seguir el principio de equidistancia. Australia, por su parte, defendía la idea de que se trataba de dos plataformas, separadas por la fosa de Timor, como quedó acreditado con estudios submarinos. Sucede que la fosa de Timor discurre muy próxima a esta isla, dejando dos plataformas muy desiguales, hasta el punto de que podría decirse que casi hay una sola, la australiana. El fallo de la Corte estableció la frontera entre ambos países en una línea situada entre la de equidistancia y la fosa de Timor, mostrando un delicado equilibrio entre las dos posturas.

b. Portugal, entonces potencia colonial en Timor oriental, no participó en las negociaciones, por lo que la frontera entre esa parte de la isla timoresa y Australia quedaba pendiente. La retirada lusa y la invasión indonesia de este sector oriental en 1975 motivó un acuerdo indonesio-australiano complementario del anterior, en 1989, por el cual se fijaban tres zonas de aprovechamiento diferentes (figura 1): la zona $\mathrm{C}$ de aprovechamiento timorense, la zona $\mathrm{B}$ de aprovechamiento australiano y una zona $\mathrm{A}$ de aprovechamiento común. La Corte Internacional de Justicia aplicó aquí la jurisprudencia anterior, de 1985, en el caso de la república Libia contra Malta. Cuando en 2002 Timor Oriental (ya Timor-Leste) accede a la independencia, ratifica esas zonas de soberanía marítima fijadas y da fin a la controversia.

c. Hay otros acuerdos en los que la geomorfología submarina ha determinado el trazado de espacios de soberanía, como el firmado 


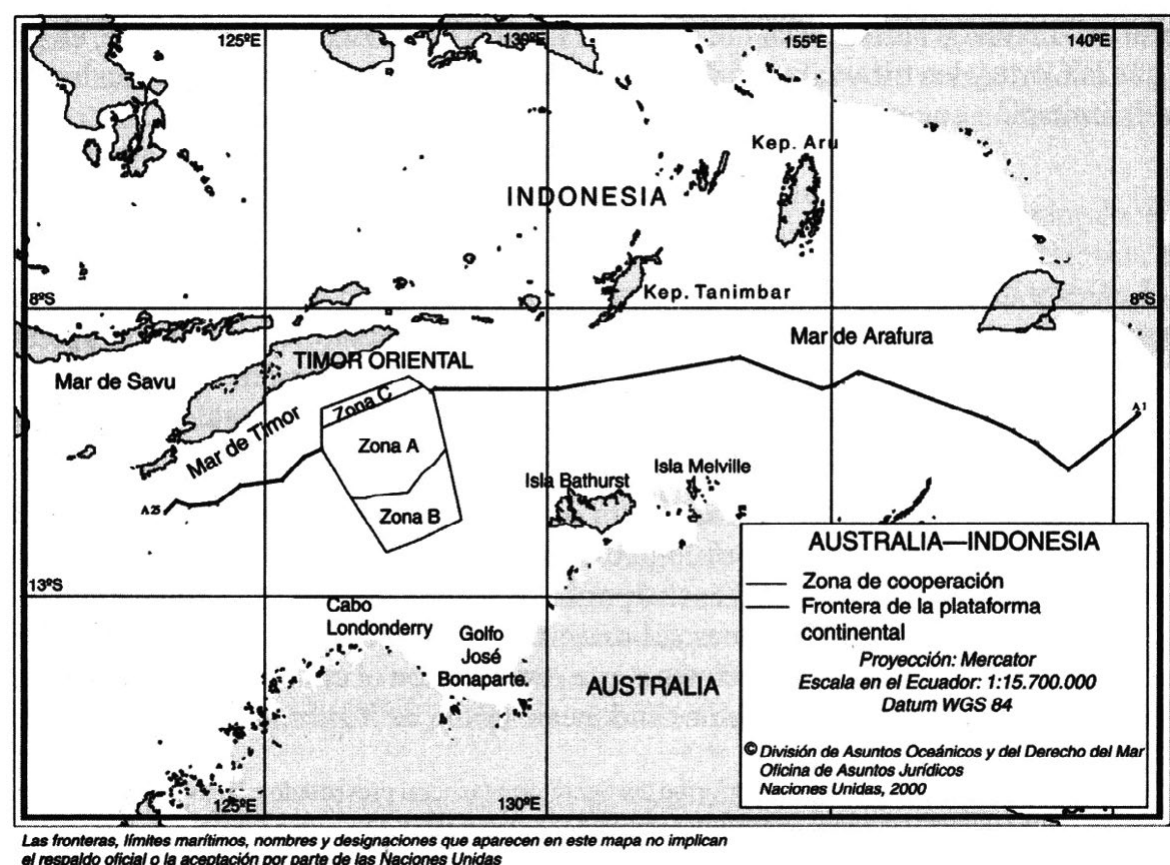

Figura 1: Delimitación de soberanía marítima entre Timor-Leste, Indonesia y Australia. Fuente: Naciones Unidas (2004), p. 38.

entre Países Bajos (por Antillas Holandesas) y Venezuela en 1978, por el que se fija el eje del canal submarino como frontera, y el de Indonesia y Tailandia por el mar de Andamán en 1975. Pero en total no llegan a la decena el número de casos en los que esto se ha producido. Por eso se dice que no es el mar, sino la tierra, quien define las fronteras en los océanos.

3. Para ello, el procedimiento que deben seguir las naciones ribereñas es el de prolongar mar adentro sus fronteras terrestres, en el sentido y dirección que tienen en el momento en que contactan con la costa. Esta prolongación se conoce como proyectar la costa (Lacleta, 2004), Las proyecciones pueden ser frontales (hacia el norte y/o hacia el sur), o laterales (este-oeste). En cuanto a las laterales, lo cierto es que muy pocos estados (Australia, Sudáfrica, Canadá y EE.UU.) pueden hacer las proyecciones laterales sin interferir con estados próximos, mientras que otros sólo pueden proyectarse lateralmente en uno de los dos puntos cardinales (Namibia, Angola, Ecuador, Perú y Chile hacia el oeste, y Japón hacia el este). Por lo que respecta a las proyecciones frontales, en sentido meridiano, ningún estado en el mundo puede realizar ambas, y 
sólo unos pocos (Sri Lanka, India...) pueden proyectarse hacia el sur. En todos los demás casos, las naciones deben alcanzar acuerdos de reparto de las aguas intermedias, basados unas veces en la normativa internacional (que da instrucciones generales, como veremos), o bien mediante acuerdos específicos bilaterales, no siempre equitativos.

\section{Los primeros documentos sobre soberanía maritima}

El concepto de soberanía maritima es reciente (desde un punto de vista histórico) y está ligado a la aparición de los estados-nación, tras la paz de Westfalia (1648). Previamente, sin embargo, existen algunos documentos de interés que representan los primeros intentos por codificar la titularidad de los mares y que han sentado las bases de la normativa actual.

Las Instituta y la consideración de las cosas comunes

El primer documento histórico en el que se establece la pertenencia de las aguas marinas es el compendio de leyes realizado bajo el imperio de Justiniano I con el nombre de Instituta o Instituciones, mandadas recopilar por este emperador en torno al $530 \mathrm{dC}$. En ellas se recoge que según el derecho natural, son cosas comunes a todos el aire, el agua que corre, el mar y sus costas. A ninguno le está prohibido acercarse a las costas del mar con tal de que se abstenga de ofender a las aldeas, monumentos y edificios, porque no son, como el mar, del derecho de gentes.

Queda establecido, pues, que el mar y sus costas son res communes (cosas comunes), que es el término que identifica a aquellos elementos cuya propiedad y uso son de todos, frente a las res nullius (o cosas de nadie), que son aquellas cuya propiedad no es de nadie y que son susceptibles de ser aprovechados por todos, como por ejemplo la caza. Esta distinción es importante, porque de las res communes derivará siglos más tarde el dominio público, en el que la propiedad y el uso son, por ser comunes, de todos.

Sassoferrato: el primer delimitador

Durante esta etapa, la principal contribución en materia de soberanía marítima se debe al jurista Bartolo (o Bártolo) de Sassoferrato (1313-1357). Considerado uno de los juristas más relevantes e influyentes de la historia (Cerezo, 1977), la figura de Sassoferrato reviste enorme importancia entre otras cosas por ser la primera persona que establece un límite de jurisdicción marina, al actuar como árbitro en la controversia entre Venecia y Génova. Ambas ciudades rivalizaban comercial y militarmente, y se acusaban mutuamente de ataques a sus flotas; la falta de acuerdo generaba enormes perjuicios comerciales en ambas ciudades, que acordaron someterse al criterio del mayor experto en leyes del momento. 
Bartolo de Sassoferrato propone, y así fue aceptado, que cada una de las ciudades dispusiera de una franja de seguridad alrededor de su puerto cifrada «en lo que navegara una nave en tres días», lo que podría razonablemente equivaler a un centenar de millas náuticas $(185 \mathrm{~km})$.

\section{El iusnaturalismo en la determinación de los límites marinos}

El siglo XV se caracteriza por una enorme expansión de las tierras conocidas por los europeos. El portugués Bartolomé Días dobla el cabo de Buena Esperanza en 1482, siendo el primer occidental en circunnavegar África, y diez años después las tres naves comandadas por Colón cruzarán el Atlántico. Nuevos territorios, y con ellos nuevos mares, forman parte de la disputa entre España y Portugal, a la que se suman algunas otras naciones de la época. El argumento más empleado será el del dominio efectivo: sobre las tierras, una nación puede ejercer un dominio efectivo porque puede instalar una vigilancia permanente (un destacamento militar, una pieza de artillería, un fortín). Sobre el mar, evidentemente no. Por tanto se plantea la duda de a quién pertenecen las aguas de los mares, puesto que nadie puede ejercer un dominio efectivo ni tomar posesión de ellas plantando una bandera y reclamándolas en nombre de la Corona.

De acuerdo con la tradición, los juristas de la época impondrán una interpretación religiosa, basada en el iusnaturalismo o derecho natural, según el cual el mar y sus recursos son parte de la naturaleza y por tanto creación de Dios. Es voluntad divina, pues, haber bendecido a esos países con dichos recursos, como un regalo, y no corresponde al ser humano cuestionar esta decisión. Habrá países que interpreten literalmente este argumento, especialmente la escuela inglesa de juristas, que inicia así un corpus teórico tendente a la apropiación de espacios marinos allí donde tengan espacios terrestres.

Otras naciones, por el contrario, y muy especialmente España y Portugal considerarán que la voluntad de Dios sólo puede ser conocida a través de sus representantes en la tierra, particularmente el más prominente de ellos. Y conviene recordar que a finales del siglo XV el Papa es Alejandro VI, Rodrigo Borgia, fiel aliado de los Reyes Católicos. No es de extrañar, pues, que el documento elaborado por el Papa, la bula Intercaetera (o Intercátedra) resulte especialmente favorable a la joven Corona española y le asigne, interpretando el derecho natural, todas las tierras y mares que queden al oeste de Azores y Cabo Verde. Aunque hay una cierta imprecision geográfica ${ }^{7}$, la bula -promulgada en 1493 - refleja claramente el apoyo papal a la expansión española mediante la cesión de la soberanía de las nuevas tierras y mares que se descubrieran, y sienta

7. Azores y las islas de Cabo Verde no están en el mismo meridiano, ni se indica qué punto de estas islas se toma como referencia. Tampoco queda claro si por Cabo Verde se entiende el archipiélago o el cabo africano. 
las bases para la firma, al año siguiente, del Tratado de Tordesillas por el que España y Portugal se reparten las tierras del nuevo continente.

Con todo, la principal característica de la bula es que representa un retroceso claro frente a los avances anteriores: se contraviene la consideración de los mares como res communes establecida por Justiniano casi mil años antes, y se deja de lado el principio de seguridad y quid pro quo marcado por Sassoferrato. Los mares, merced a la intervención papal, resultan tener propietario.

\section{Los mares libres: Vázquez de Menchaca y Hugo Grocio}

No fue, sin embargo, una doctrina unánimemente aceptada en la época. La evidente motivación política de la bula Intercaetera generó rechazo en otras naciones, e incluso discrepancias en juristas españoles como el vallisoletano Fernando Vázquez de Menchaca, quien en torno a $1560^{8}$ edita sus Controversias fundamentales donde aborda diferentes problemas del Derecho y, entre otros, la posesión de los mares, declarando que el mar debe ser libre porque las leyes humanas no pueden imponerse a la voluntad de Dios, pues según Vázquez de Menchaca cada individuo tiene libertad de acción (id quod libet), sin más limitaciones que la prohibición de violar la Ley Natural (Carpintero, 1974). Y como la Ley Natural sostiene que los mares son creación de Dios, las acciones humanas deben quedar sometidas a ella.

La interpretación de Vázquez de Menchaca se sustenta, pues, en el derecho natural, y sienta las bases de la conocida teoría de los mares libres establecida por el neerlandés Hugo Grocio quien sin embargo es mucho más conocido por esto que el vallisoletano, a pesar de que su obra sea casi medio siglo posterior?. En efecto, entre 1604 y 1605 Huig Van der Groot (Hugo Grocio) escribe De jure proede, una magna obra que no fue publicada íntegramente hasta 1868, mucho después de su muerte. Sin embargo, sí se dio a conocer por partes desglosadas, y de ella se difundió un pequeño opúsculo titulado Mare liberum del duodécimo capítulo (De iure praede commentarius), escrito en 1606 y publicado tres años después. En este celebérrimo opúsculo Grocio establece la necesidad de que el tránsito por los mares sea libre, por aguas que no pertenezcan a ninguna nación. El motivo argumentado es, de nuevo, la imposibilidad de ejercer un dominio efectivo y prolongado sobre las aguas del mar, sólo que esta vez sustentado en la doctrina del derecho natural, emanado de la ley divina, a partir de estudios anteriores, como las Controversias de Vázquez.

8. Hay dos ediciones de las Controversias, la de Barcelona de 1563 y la veneciana, de 1564. La fecha en la que fueron redactadas es desconocida, aunque evidentemente anterior.

9. Barcia (1932) ya indicaba hace ochenta años que debía repararse este olvido, pues «el nombre de Grocio aparece indefectiblemente unido a la causa de la libertad oceánica, en tanto que muy excepcionalmente se menciona en tal sentido a Vázquez de Menchaca». 
Los motivos de Grocio, sin embargo, no sólo eran espirituales. De hecho, tras la teoría de los mares libres se esconde el interés comercial neerlandés por que las rutas marítimas interoceánicas no se vieran perjudicadas con la aparición de espacios de soberanía de otras naciones y, eventualmente, que esto aumentara los riesgos en el comercio o un aumento de costes. Para explicar esto, conviene contextualizar la doctrina de Grocio en su momento histórico: en 1602 se había fundado la Compañía Holandesa de las Indias Orientales, en la que Grocio trabajaba como abogado y cuyos intereses defendía. La Compañía tenía especial interés en desarrollar esta doctrina, y en difundir las investigaciones de Grocio tan pronto como fuera posible, sobre todo para anular a sus rivales comerciales más directos, Portugal y España, beneficiados por la injerencia papal y que aseguraban que el solo descubrimiento otorgaba posesión, sin necesidad de ejercer un control o dominio efectivo. Las consecuencias de la formulación de Grocio fueron esencialmente dos (García Arias, 1964) ${ }^{10}$ :

- La primera, forzó las negociaciones entre España y las Provincias Unidas (Países Bajos) que concluyeron con la firma de la Tregua de los Doce Años en Amberes el 9 de abril de 1609, por la cual España garantizaba libertad de navegación a los buques neerlandeses.

- En segundo lugar, forzó a los británicos a adoptar una política restrictiva de la libertad de pesca $-\mathrm{y}$ de los mares en general- mediante la promulgación el 6 de mayo de 1609, de una Proclama de Jacobo I, que acrecentó la rivalidad comercial entre las dos Compañías de las Indias Orientales, la británica y la holandesa.

\section{La reaccion británica: los mares cerrados}

Resulta conocida la airada reacción británica a los postulados de Grocio, que llevó incluso al rey Carlos I de Inglaterra a proponer su excomunión y procesamiento. El peligro no era pequeño: su creciente imperio colonial ya se extendía, en el siglo XVII, por todos los océanos y continentes, de forma que la libertad de navegación propuesta por Grocio constituía una amenaza para el poderoso dominio comercial británico.

La primera respuesta vino del escocés William Welwod, en su obra De dominio maris (1615), en la que acusó a Grocio de justificar la pesca abusiva de los Países Bajos en aguas de Escocia, apelando a esa presunta ausencia de soberanía sobre las aguas del mar. Pero la réplica más conocida provino de la obra Mare clausum, de John Selden, destacado jurista inglés que recibió directamente del rey Jacobo I el encargo de rebatir a Grocio. La respuesta, terminada en 1618, no fue publicada hasta 1635 , presumiblemente porque las tesis contrariaban los

10. Cit. por Salom (2001). 
intereses de los monarcas de Holanda con quienes el rey Jacobo mantenía estrechos lazos de amistad.

Selden sostenía, a diferencia de la interpretación justinianea, que los mares no son res communes o sea de toda la humanidad, y aunque reconocía como especial el derecho de paso, propuso que el mar, como la tierra, fuera susceptible de apropiación y por lo tanto objeto de dominio privado (Salom, 2001) admitiendo sólo como res communes el aire supramarino. Y respaldaba esta afirmación con el hecho de que Gran Bretaña ya había demostrado ser capaz de ejercer un dominio efectivo (dominium) en mar abierto, más allá de las islas de su entorno, además de que la costumbre internacional y la práctica de las naciones se inclinaba mayoritariamente por el dominio y apropiación del mar. Precisamente, la coincidencia aquí con las tesis de España y Portugal (amenazadas por los postulados de Grocio) será la que concite la conjunción de intereses entre estas naciones, y el éxito, al fin, de los postulados de Selden, que se concretarán poco a poco en los siglos siguientes en el establecimiento de límites de soberanía.

\section{Las primeras zonas de soberanía}

Decidida -no sin discrepancias- la conveniencia de cerrar los mares, quedaba pendiente lo más importante: determinar sobre qué espacio las naciones podrían reclamar ser titulares de los derechos de soberanía y explotación. Habrá que esperar hasta 1702 para que de nuevo un jurista holandés, Cornelius Van Bynkershoek establezca que una nación puede decirse soberana en el mar hasta el punto en el que sea capaz de ejercer de manera efectiva su dominio; por lo tanto, el lugar que pueda ser controlado por una batería instalada en la costa. Esto es lo que se ha conocido popularmente como la regla del alcance de la bala de cañón. La norma, en principio razonable, resultaba sin embargo de imposible aplicación, pues no todas las naciones tienen (ni entonces ni ahora) igual potencia de fuego, y una misma nación varía dicha potencia en función de los avances técnicos que se sucedan a lo largo de los años ${ }^{11}$.

Ochenta años después, en 1782, el abad Ferdinando Galeani equiparó ese alcance con tres millas náuticas (aproximadamente 4' $8 \mathrm{~km}$ ), en lo que constituye el primer establecimiento de límites de soberanía marítima desde que Sassoferrato resolvió la disputa entre Génova y Venecia. Las tres millas

11. El alcance de la bala de cañón en realidad no fue nunca aplicado, aunque ha habido algún caso en el que una nación lo ha empleado como argumento. El más próximo es el de Inglaterra (act. Reino Unido), que históricamente ha considerado que su soberanía en Gibraltar se extiende hasta donde alcance un proyectil disparado desde la cumbre de la roca, aunque esto no figura en el artículo 10 de Tratado de Utrecht por el que la Corona española cedía la Roca a perpetuidad. 
náuticas todavía rigen en algunas zonas del mundo, como Australia Meridional o Queensland. Sin embargo, Lacleta (2004) indica con acierto que los cañones más habituales en los navíos del XVIII tenían una potencia de fuego en torno a 250 metros, por lo que difícilmente las tres millas podían ser el desarrollo de la formulación de Van Bynkershoek. Más bien, las tres millas náuticas vienen a coincidir con la distancia a la que el ojo humano puede atisbar la presencia del velamen de una embarcación desde la costa, en condiciones óptimas de visibilidad y teniendo en cuenta la curvatura de la Tierra. Por lo tanto, el umbral de tres millas náuticas es, razonablemente, un umbral de seguridad defensivo, más que de ejercicio ofensivo.

Tampoco todas las naciones aceptaron esa línea de tres millas náuticas. Sin ir más lejos, España en 1770 fijó en dos leguas marinas (seis millas náuticas) la anchura de sus aguas jurisdiccionales, arcaico término que hoy designa a las aguas territoriales o de soberanía marítima. Esta anchura se mantendrá durante dos siglos, hasta que en 1977 se apruebe la ley 10/1977, de 4 de enero, sobre el Mar Territorial ${ }^{12}$. Es decir, a pesar de los esfuerzos por codificar este asunto no ha habido consenso entre las naciones... al menos hasta la aprobación de la Carta de las Naciones Unidas.

\section{LA SOBERANÍA MARÍTIMA EN LA ACTUALIDAD}

El primer intento de acuerdo internacional se produce en la reunión de la I Conferencia de las Naciones Unidas sobre Derecho del Mar (I CNUDM), celebrada en Ginebra en 1958. Tras varias sesiones de debate, se sometieron a votación cuatro convenios, de los cuales sólo dos obtuvieron la mayoría necesaria de dos tercios de la Asamblea General para ser aprobados: el convenio sobre la Plataforma Continental (mencionado al principio de este trabajo) y el convenio sobre la Alta Mar. Quedaron pendientes de aprobación los convenios más conflictivos, el relativo al Mar Territorial (y con él la zona contigua) y el que se dedicaba a la Pesca y Conservación de los Recursos Vivos en Alta Mar.

La falta de acuerdo motivó que la Asamblea General de las Naciones Unidas aprobara la resolución 1307/58, por la que se convocaba a una II CNUDM. Esta segunda Convención se celebró de nuevo en la ciudad de Ginebra, en 1960, pero con menor éxito aún que la anterior. El desacuerdo básico estribaba en la anchura asignada al Mar Territorial, zona de soberanía marítima plena que algunos estados querían fijar en doce millas náuticas, mientras otros -como Ecuador, Chile y Perú- proponían llevarla a máximos de 200 y algunos otros, como EE.UU., no consideraban que debiera exceder de 6 millas náuticas.

12. Disponible en http://noticias.juridicas.com/base_datos/Admin/110-1977.html 
Por fin, en 1973 se reunió en Caracas la III Convención de las Naciones Unidas sobre Derecho del Mar, con el propósito de alcanzar un acuerdo de consenso acerca de los límites de la soberanía marítima, a pesar de que las posturas permanecían enfrentadas. Aglutinó a 160 estados, y constituye aún hoy el acuerdo más debatido en la Asamblea General puesto que las sesiones se prolongaron durante nueve años. Las discrepancias eran tan abiertas que Venezuela, país convocante y anfitrión, abandonó las negociaciones, lo que obligó a continuar los debates en Jamaica, donde se alcanzó un acuerdo, en la localidad de Montego Bay, en 1982. Por ese motivo se suele conocer a la III CNUDM como Convención de Montego. El documento final, que consta de 320 artículos y nueve anexos, recibe habitualmente el nombre de Ley del Mar ${ }^{13}$, o más ampulosamente, el de Constitución de los Océanos. Aunque la firma protocolaria se hizo en Nueva York el 30 de abril de 1982, el documento quedó abierto a la firma de las naciones que quisieran adherirse como primeros firmantes durante más de dos años, hasta el 9 de diciembre de 1984, en un primer momento en el Ministerio de Relaciones Exteriores de Jamaica (desde el 10 de diciembre de 1982) y después en la Sede de las Naciones Unidas en Nueva York, ya desde el 1 de julio de 1983 (Naciones Unidas, 2008).

El documento fue negociado por la vía del consenso; es decir, una nación firmante debía adherirse completamente a todo el articulado y sus anexos; así se evitaba una aprobación parcial, como sucedió con el texto de 1958 (I CNUDM). La Ley del Mar fue aprobada por 130 votos a favor, 17 abstenciones ${ }^{14}$ y cuatro votos negativos ${ }^{15}$, pero, a pesar de esta mayoría, el documento no entraría en vigor hasta el 16 de noviembre de 1994, 12 meses después del depósito del sexagésimo instrumento de ratificación (Bosnia-Herzegovina) (Naciones Unidas, 2008). Actualmente (noviembre de 2015) lo han ratificado 167 naciones de un total de 193 estados miembros en la Asamblea General, aunque siguen sin hacerlo Turquía, Estados Unidos, Israel, Venezuela, Colombia, Corea del Norte, Siria, Irán, Taiwan y Perú.

\section{Las líneas de base}

El establecimiento de las zonas de soberanía marítima en la III CNUDM requiere el trazado previo de un perfil suavizado de la línea de costa, en el que se mitiguen sus escotaduras, bahías, rías y ensenadas. Esto se consigue mediante las llamadas

13. Law of the Seas (o su acrónimo LOS) es, de hecho, como se conoce el tratado en Naciones Unidas. Puede consultarse el texto íntegro, en castellano, en la dirección siguiente: http:// www.un.org/Depts/los/convention_agreements/texts/unclos/convemar_es.pdf.

14. Se abstuvo el bloque soviético, excepto Rumanía y Yugoslavia, así como España, Italia, Alemania, Países Bajos y Bélgica.

15. Votaron en contra Estados Unidos, Israel, Turquía y Venezuela. Ninguno de ellos ha ratificado la Convención de Montego hasta la fecha. 
lineas de base, segmentos imaginarios que determinan el lugar desde el cual comenzarán a realizarse las mediciones para establecer espacios de soberanía.

Las líneas de base pueden ser de dos tipos: normales y rectas. Las líneas de base normal se trazan por donde llegan las aguas en bajamar. En litorales macromareales esta línea de base puede apartarse apreciablemente de la costa emergida, pero por lo general su discurso suele ser próximo a tierra. Por este motivo, la mayor parte de los estados prefiere el empleo de las líneas de base rectas, aunque en principio deberían restringirse sólo a las costas con profundas escotaduras y perfil muy recortado. Las líneas de base rectas unen los puntos prominentes del litoral, generalmente cabos, y suelen discurrir mucho más lejanas a tierra permitiendo que el inicio de los espacios de soberanía comience lo más lejos posible del continente.

La capacidad de los estados de decidir, en última instancia, qué tipo de línea de base eligen y cuál es su trazado es buena prueba de la ambigüedad calculada con la que se redactó el texto de la III CNUDM. Así, se dice que las líneas de base rectas deben unir los puntos apropiados, y no se indica cuál debe ser su longitud (se habla de 24 millas náuticas, pero sólo en el caso de líneas que cierren bahías) ni su trazado, del que sólo se dice que no deberá alejarse apreciablemente de la dirección general de la $\operatorname{costa}^{16}$. No obstante esto, Suárez de Vivero ya apuntaba que este criterio se ha contravenido en ocasiones, y que existen casos extremos en el trazado de líneas de base recta, entre los que cita los ejemplos de Venezuela y Birmania, que han trazado líneas de 98 '9 y 222'3 millas náuticas respectivamente, «dándose el caso de que algunas de estas líneas no se apoyan en puntos salientes de la costa, sino que se sitúan sobre las aguas (Ecuador, Birmania)» (Suárez de Vivero, 2001).

En el caso de los estados archipelágicos se concreta algo más, pues las líneas de base deberán ser menores a 100 millas (aunque un $3 \%$ de ellas podrán superar ese umbral, siempre que no alcancen 125), y deberán comprender las islas principales, pero incluso así la interpretación es bastante abierta y permite a estados como Japón o Filipinas trazar líneas de base ciertamente ambiciosas.

\section{Espacios de soberanía marítima según la III CNUDM}

Las aguas interiores (AI)

El trazado de las líneas de base rectas deja entre ellas y las tierras emergidas un espacio marino que recibe el nombre de aguas interiores. Cuentan a efectos de superficie igual que las aguas continentales y las tierras emergidas y, en el caso de España, su gestión corresponde a las comunidades autónomas, aunque pertenezcan al dominio público marítimo terrestre estatal -por tanto son de soberanía

16. III CNUDM, art. 7. 


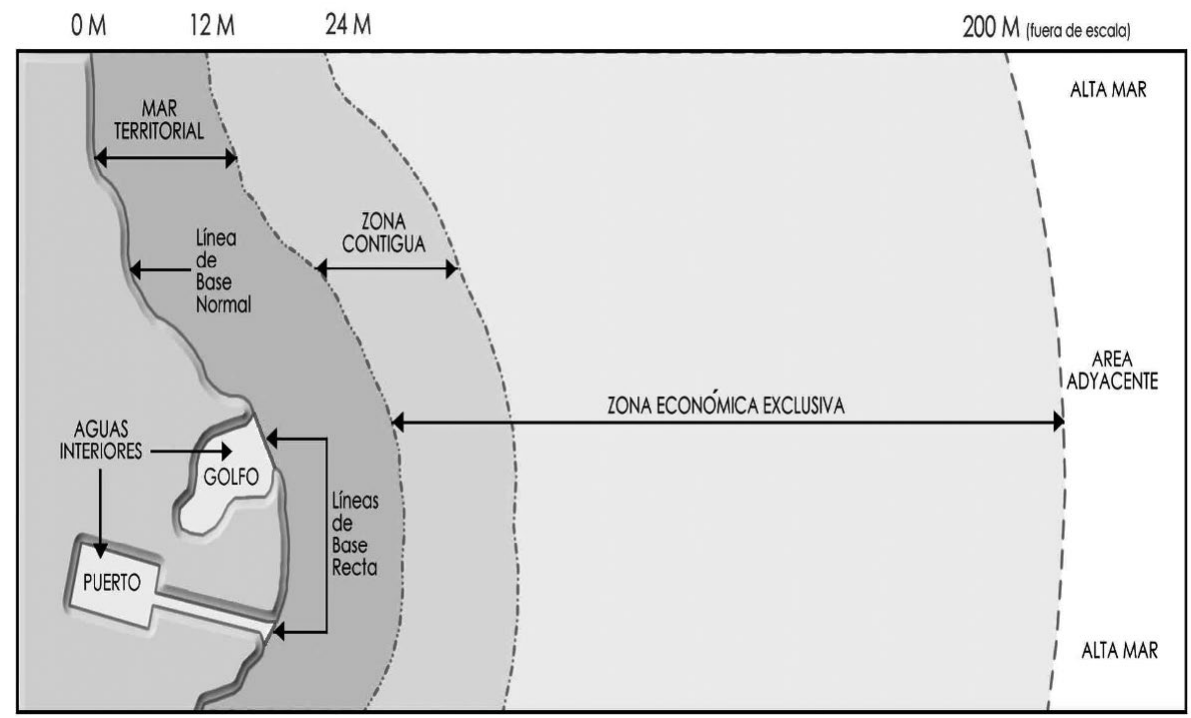

Figura 2: Esquema básico de las zonas de soberanía marítima establecidas en la III Convención de las Naciones Unidas sobre Derecho del Mar. Fuente: Armada argentina, Régimen jurídico de los espacios maritimos, en http://www.ara.mil.ar/archivos/Docs/IIMM-01-Capitulo\%201.pdf

nacional y uso público-, si bien se consienten usos en régimen de concesión administrativa (habitualmente marisqueo, acuicultura...)

\section{El Mar Territorial (MT)}

Tradicionalmente llamado aguas jurisdiccionales o aguas nacionales el mar territorial constituye el espacio marítimo comprendido entre las líneas de base y, como máximo, las doce siguientes millas náuticas. Forma parte igualmente del dominio público marítimo terrestre, y conviene resaltar que la soberanía de la nación ribereña es plena tanto en el aire suprayacente, como en la superficie marina, la columna de agua, el lecho marino y el subsuelo submarino. En esos cinco espacios rige la jurisdicción nacional a todos los efectos, y en el caso español, la gestión es estatal, no autonómica.

Lo más destacable del mar territorial es que, para no entorpecer la navegación, se contempla en él el derecho de paso inocente. Este derecho asiste a las embarcaciones de otros, y les faculta para transitar libremente, sin necesidad de solicitar autorización, por el mar territorial de otras naciones siempre y cuando este tránsito cumpla dos condiciones:

- Debe ser ininterrumpido. Sólo se consiente la detención o el fondeo si se trata de un incidente normal de la navegación o por razones de fuerza 
mayor (malas condiciones de oleaje para la navegación, una avería mecánica, o para auxiliar a personas o embarcaciones en peligro o a la deriva).

- No debe ser perjudicial para la paz, el buen orden o la seguridad del estado por cuyo mar territorial transitan. Se entienden como actividades perjudiciales para la seguridad los ejercicios con prácticas con armas de cualquier clase, los actos de propaganda, las amenazas o ataques, lanzar o recibir aeronaves o embarcaciones (del tipo que fueran), las actividades de pesca o extractivas y embarcar/desembarcar productos, monedas o personas, contraviniendo la legislación aduanera.

\section{La Zona Económica Exclusiva (ZEE)}

Se trata del espacio comprendido entre las líneas de base y las 200 millas náuticas. No es una zona acumulable a la anterior, de manera que, en realidad, adquiere la denominación de ZEE un espacio de 188 millas desde el límite exterior del mar territorial, no de 200. La principal diferencia con él es que en el caso de la Zona Económica Exclusiva la soberanía nacional está limitada tan sólo a los recursos marinos (vivos o no), y no a la zona aérea, la superficie marina, la columna de agua, el lecho ni el subsuelo submarino como sí ocurría en el mar territorial. La jurisdicción nacional, pues, sólo es aplicable en la medida en que afecte a la defensa, conservación y gestión de los recursos. En todo lo demás, rige la legislación del estado al que pertenezca el pabellón del barco ${ }^{17}$.

El estado ribereño tiene derecho a explotar, explorar, conservar y administrar los recursos que encuentre en esa zona, pero no es soberano de sus aguas ${ }^{18}$. Por tanto, no cabe solicitar el derecho de paso inocente porque las demás embarcaciones pueden transitar libremente al no ser aguas nacionales.

\section{La Plataforma Continental (PC)}

La soberanía de una nación en el caso de la plataforma continental es muy similar a la de la zona económica exclusiva, puesto que ésta se limita a los recursos económicos (vivos o no), y no realmente al espacio marino. Como veíamos al principio, la PC tiene unos límites físicos precisos, independientes de las distancias medidas desde la costa. Puede ocurrir, pues, que no alcance las 200 millas náuticas y en ese caso no exista plataforma más allá de la ZEE. Salvo

17. Así, un delito cometido en una embarcación deberá ser juzgado por el estado ribereño si se produce dentro de mar territorial, o bien por el estado de la bandera del buque si se comete fuera de él.

18. Se puede, también, establecer islas artificiales, pero éstas nunca pueden entorpecer la navegación ni sirven para declarar a su alrededor espacios de soberanía como mar territorial o ZEE. La construcción de dichas islas deberá ser comunicada, y podrán ser protegidas con estructuras de seguridad siempre que éstas no disten más de $500 \mathrm{~m}$. de la isla artificial. 
en esa circunstancia, la plataforma se extiende a continuación de la ZEE, hasta donde se alcancen los $200 \mathrm{~m}$. de profundidad, o bien hasta donde comience la pendiente submarina a aumentar en el talud continental, siempre y cuando no exista colisión de intereses con otro/s estado/s, en cuyo caso procede establecer un acuerdo entre ambas naciones. Si no son capaces de alcanzar un acuerdo, pueden someterse al criterio de un árbitro internacional -cuyo dictamen sea aceptado por ambas partes-, o cuando esto tampoco es posible, se resuelve la controversia en la Corte Internacional de Justicia.

Lo más interesante de la plataforma es la capacidad que tienen los estados de solicitar su ampliación, siempre que ésta se extienda más allá de las 200 millas náuticas en las que termina la ZEE, y siempre que, además, esta ampliación no suponga merma de los derechos de otro estado. Este recrecimiento de la plataforma se puede solicitar aplicando uno de los dos siguientes criterios, el que resulte más favorable: o bien ampliar la plataforma hasta las 350 millas náuticas (contadas desde las líneas de base), o bien ampliarla 100 millas náuticas desde el punto en el que se encuentra la isobata de $2500 \mathrm{~m}$. de profundidad ${ }^{19}$. Para ello el estado deberá preparar toda la documentación y entregarla al Secretario General de las Naciones Unidas en un plazo de diez años desde el momento en que el estado se adhirió a la III CNUDM ${ }^{20}$.

\section{Alta Mar}

El resto de las aguas marinas del mundo (en realidad su superficie), no comprendidas en ninguna de las categorías anteriores, recibe la consideración de alta mar. En ella, todos los estados (costeros o no) tienen derecho de navegación y sobrevuelo $\mathrm{y}$, acatando las convenciones necesarias (por ejemplo sobre pesca y especies protegidas), también tienen derecho de pesca, de investigación científica, de construir islas artificiales y otras instalaciones, de tender cables y tuberías submarinas...

La alta mar, por tanto, escapa al concepto de soberanía marítima estrictamente, puesto que ningún estado podrá reclamarla (art. 89), ni ejercer dominio efectivo. Es más, las Naciones Unidas sólo contemplan que sea utilizada con fines pacíficos (art. 88). No obstante, los buques que transitan por ella gozan de completa inmunidad de jurisdicción, y esto incluye a los navíos de guerra, que pueden realizar maniobras o ejercicios, y a los barcos de pesca, que pueden faenar libremente, acatando, eso sí, las legislación existente sobre especies protegidas. No obstante, si se sospecha que están realizando alguna actividad delictiva (tráfico de drogas, de armas o de personas) ${ }^{21}$, entonces a los demás

19. III CNUDM, art. 76 .

20. III CNUDM, anexo II, art. 4.

21. Aunque esas son las actividades delictivas más habituales, la III CNUDM sin embargo enumera las siguientes: la piratería, el tráfico de esclavos, realizar transmisiones no autorizadas y ausencia de pabellón. 
navíos les asiste el derecho de visita: pueden lanzar una lancha, al mando de un oficial, para abarloarse al buque sospechoso y realizar un reconocimiento. Si resulta en vano, se contempla la posibilidad de indemnización por daños y perjuicios causados al barco visitado (por ejemplo, por la demora).

\section{La Zona}

Recibe el nombre de la zona el espacio sumergido de la alta mar, quedando esta última limitada sólo a la superficie marina. La zona incluye el lecho marino y el subsuelo, y se considera, tanto ella como sus recursos, "patrimonio común de la humanidad» (art. 133 y siguientes). No obstante esta protección, estos recursos pueden ser extraidos siempre que se haga «en beneficio de la humanidad», especialmente «de los países en desarrollo y aquellos que no han logrado la independencia», y siempre que se fomente «el desarrollo saludable de la economía mundial y el crecimiento equilibrado del comercio internacional» (art. 150).

\section{CONCLUSIÓN}

A lo largo de las páginas precedentes se han recopilado los diferentes hitos históricos que han contribuido a definir la soberanía marítima actual. Como habrá podido verse, se trata de espacios que, aunque inicialmente fueron considerados res communes, es decir, lugares cuya propiedad y usos son de todos, en la actualidad (y sobre todo desde la obra de John Selden, en torno a 1630) se les atribuye capacidad de ser controlados por los estados, y, por tanto, objeto de soberanía. Ésta ha variado a lo largo de la historia, concretándose en la actualidad en una serie de franjas, paralelas entre sí, que se comienzan a contar desde el trazado de unas líneas imaginarias o líneas de base que atenúan el perfil recortado de las costas. Pocos asuntos han sido tan controvertidos en la historia de las relaciones internacionales como el de la soberanía marítima. Incluso hoy, que se encuentra ampliamente codificada, el hecho de que algunas naciones de gran relevancia militar y económica no hayan suscrito los acuerdos internacionales, impide una correcta aplicación de éstos. En la mayor parte de los casos, las controversias se resuelven en la Corte Internacional de Justicia, o bien directamente quedan enquistados y no se plantean porque las naciones afectadas no aceptan dicha jurisdicción, o se niegan a iniciar negociaciones.

\section{REFERENCIAS}

Barcia Trelles, Camilo (1932): Fernando Vázquez de Menchaca (1512-1569). Comunidad internacional, imperio y libertad de los mares. Anales de la Universidad de Murcia, n. $^{\circ}$. Servicio de Publicaciones de la Universidad de Murcia. Murcia, 12 p. Disponible en http://hdl.handle.net/10201/6306. 
Barragán Muñoz, Juan Manuel y De Andrés, María (2016): «Aspectos básicos para una gestión integrada de las áreas litorales de España: conceptos, terminología, contexto y criterios de delimitación», en Revista de Gestão costeira integrada Journal of Integrated Coastal Zone Management. Aveiro, Portugal, 13 p. Versión pre-publicada en http://www.aprh.pt/rgci/pdf/rgci-638_Barragan.pdf.

Carpintero Benítez, Francisco (1974): «La función del Derecho en Fernando Vázquez de Menchaca», en Anuario de filosofía del derecho, n. ${ }^{\circ}$ 17, pp. 9-14. Disponible en línea en: http://dialnet.unirioja.es/servlet/articulo?codigo=2064825

Cerezo de Diego, Prometeo (1977). «Orígenes de la teoría del Mar Territorial en Bártolo de Sassoferrato», en Revista Española de Derecho Internacional, vol. 30, n. ${ }^{\circ} 2-3$, pp. 237-256.

EPYPSA (1999): Directrices de actuación en el litoral de la Comunidad Valenciana Conselleria d'Obres Públiques, Urbanisme i Transports. Documento inédito. 109 p.

García ArIAS, Luis (1964): Estudios de historia y doctrina del derecho internacional, Instituto de Estudios Políticos, Madrid, 219 p.

ITUR (1987): Análisis del litoral español. Diseño de políticas territoriales. Ed. Instituto del Territorio y el Urbanismo (MOPU), Madrid, $243 \mathrm{p}$.

JUNTA DE ANDALUCÍA (1990): Directrices regionales del litoral de Andalucía. Consejería de Obras Públicas y Transportes de la Junta de Andalucía. Sevilla, 175 p (más anexo cartográfico).

LACleTA MuÑoz, José Manuel (2004): «Las fronteras de España en el mar», Documento de trabajo $n .^{\circ} 34 / 2004$. Real Instituto Elcano. 28 p. Disponible en línea: [http:// www.realinstitutoelcano.org/documentos/121/121.pdf]

LEY 22/1988, de 28 de julio, de Costas.

MARTín RuIZ, Juan Francisco (2005): «Los espacios marítimos y el problema de su delimitación en la posición geopolítica del archipiélago canario», en Scripta Nova, Revista electrónica de Geografía y Ciencias Sociales, vol. IX, núm. 185. Universidad de Barcelona. Disponible en línea: [http://www.ub.edu/geocrit/sn/ sn-185.htm]

Moore, W.G. (1957): A dictionary of Geography. Penguin Reference Books, London, $190 \mathrm{p}$.

NACIONES UNIDAS (2001): Manual de delimitación de fronteras maritimas. División de Asuntos Oceánicos y del Derecho del Mar. Oficina de Asuntos Jurídicos. Nueva York, $212 \mathrm{p}$.

NACIONES UNIDAS (2008): Convención de las Naciones Unidas sobre Derecho del Mar, United Nations Audiovisual Library of International Law. Disponible en línea en la dirección: http://legal.un.org/avl/pdf/ha/uncls/uncls_ph_s.pdf.

Salom Franco, Nicolás (2001): "Vitoria y Grocio frente al mar», en Revista de Estudios Socio-Jurídicos, vol. 3, n. ${ }^{\circ}$ 1, pp. 93-141. Universidad del Rosario, Bogotá (Colombia). Disponible on-line. Recuperado el 15 de octubre de 2015, en http://www. scielo.org.co/scielo.php?script=sci_arttext\&pid=S0124-05792001000100006\&lng $=$ en\&tlng $=$ es.

SuÁreZ de Vivero, Juan Luis (2001): Los océanos. Medio ambiente, recursos y políticas públicas. Ediciones Del Serbal (col. Estrella Polar). Barcelona, 308 p. 